\title{
Bis(pyrrole-benzimidazole) conjugates as novel colorimetric sensor for anions
}

\author{
SANJEEV PRAN MAHANTA ${ }^{\mathrm{a}, \mathrm{b}, *}$ and PRADEEPTA KUMAR PANDA ${ }^{\mathrm{b}, *}$ \\ a Department of Chemical Sciences, Tezpur University, Napaam, Assam 784 028, India \\ ${ }^{b}$ School of Chemistry, University of Hyderabad, Hyderabad, Telengana 500 046, India \\ E-mail: spm@tezu.ernet.in; pkpsc@uohyd.ernet.in
}

MS received 24 January 2017; revised 16 March 2017; accepted 21 April 2017

\begin{abstract}
Novel bis(pyrrole-benzimidazole) (PYBI) conjugates were investigated as colorimetric anion recognition motif by employing multiple donor sites. In this regard, PYBI derivatives where pyrrole unit is connected to the $\mathrm{C} 2$ position of benzimidazole via its $\alpha$-position were synthesized and their anion recognition behavior were evaluated by UV-Vis, fluorescence and ${ }^{1} \mathrm{H}$ NMR spectroscopy. PYBI selectively interacts with fluoride ion, whereas introduction of nitro group on the benzimidazole moiety enhances the binding affinity by at least one order, albeit at the expense of the selectivity. Bridging of two PYBIs led to interesting cooperative effect between the two subunits, which gets enhanced upon changing the spacer between the two from nonconjugating type $\left(s p^{3}-\mathrm{C}\right)$ to conjugating one (quinoxaline). This also affects the way they interact with anions, with the latter moiety displaying very interesting stepwise double deprotonation of benzimidazole protons upon addition of fluoride ions with strong colorimetric as well as fluorometric response. Further, acidity of the H-bond donor sites was found to play pivotal role in the anion complexation mechanism and selectivity.
\end{abstract}

Keywords. Pyrrole; benzimidazole; anion recognition; cooperative; proton migration.

\section{Introduction}

Considering the important roles of anions in biological, environmental and industrial processes, anion recognition chemistry has developed into an independent research area focused on the structure and binding modes of anions. ${ }^{1}$ The goals of these studies have been to understand specific binding behaviour, to derive structure-function relationships, to search for new anion binding motifs and, last but not the least, to find useful application as sensors. ${ }^{2}$ In the last three decades, several neutral receptors containing polarizable $\mathrm{H}$-bond donor units such as pyrrole, imidazole, phenol, amide, urea, etc., and their conjugates such as amidopyrroles, amidoureas, pyrrole-ureas were reported. ${ }^{2,3}$ Anionic guest interacts with these receptors either via $\mathrm{H}$-bond formation or via deprotonation mechanism. ${ }^{1}$ In case of $\mathrm{H}$-bonded system, the binding constant or the formation constant can be directly correlated to the stability of the complex between the receptor and anion. However, deprotonation is a Brönsted acid-base reaction and the equilibrium constant depends on the stability of the corresponding conjugate base of the receptor. With highly basic anions such as fluoride and acetate, receptors with moderately acidic $\mathrm{H}$-bond donor unit initially

\footnotetext{
*For correspondence
}

forms H-bonded complex, but in presence of excess anion, deprotonation is favoured owing to the formation of stable H-bonded anion dimers. ${ }^{3}$ The mode of interaction, i.e., $\mathrm{H}$-bonding or deprotonation, generally depends on the acidity of the $\mathrm{H}$-bond donor site of the receptor and basicity of the anion. In principle, increasing the acidity of the $\mathrm{H}$-bond donor moieties increases both H-bond donor affinity as well as the deprotonation tendency. Moreover, receptors where the negative charge delocalization can be extended to the entire molecular framework favours deprotonation. ${ }^{4}$ Deprotonation increases electron density at the receptor sites and eventually decreases the H-bonding tendency of the remaining $\mathrm{H}$-bond donor sites of the receptor.

Pyrrole and benzimidazole are widely used as $\mathrm{H}$-bond donor components in the design of artificial receptors. ${ }^{5,6}$ While pyrrole acts as an $\mathrm{H}$-bond donor, benzimidazole endowed with both $\mathrm{N}-\mathrm{H}$ and imine $\mathrm{N}$ functionalities can respectively act as both $\mathrm{H}$-bond donor and acceptor. The acidic hydrogen of benzimidazole is involved in tautomerism and thereby shuttles between the two $\mathrm{N}$ atoms. Therefore, benzimidazole binding sites could be easily oriented on the demand of the complementary binding sites of the guest. Bordwell reported $\mathrm{p} K_{a}$ of benzimidazole as 16.4 in DMSO, which is lower than that of pyrrole $\left(\mathrm{p} K_{a}=23.0\right)$, suggesting a rel- 


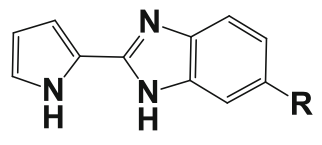

a: $\mathbf{R}=-\mathrm{H} ; \mathbf{b}: \mathbf{R}=-\mathrm{NO}_{2}$

1

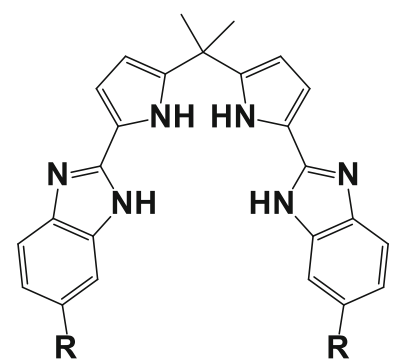

2

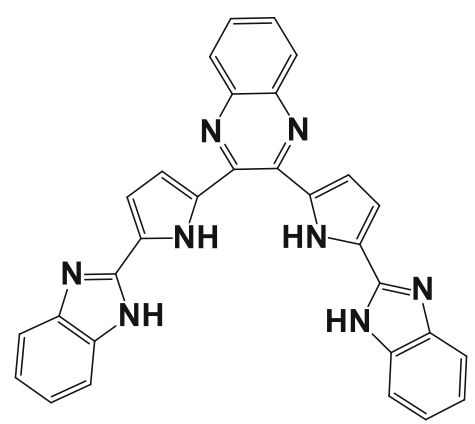

3

Figure 1. Structure of the synthesized pyrrole-benzimidazole (PYBI) derivatives.

atively stronger $\mathrm{H}$-bonding as well as deprotonation tendency of the former. ${ }^{7}$ Literature reports suggest that pyrrolic receptors interact with anions preferably via $\mathrm{H}$ bonding with some exceptions. ${ }^{5}$ Gale and co-workers reported that diamidopyrrole derivatives with electron withdrawing groups interact with fluoride via deprotonation mechanism. ${ }^{8}$ In 1999 , Sessler et al., ${ }^{9 \mathrm{~b}}$ reported that 2,3-dipyrrol-2-ylquinoxaline receptor interacts with fluoride via $\mathrm{H}$-bonding $\left(\mathrm{N}-\mathrm{H}\right.$.... $\left.\mathrm{F}^{-}\right)$with subsequent deprotonation, while other anions interact predominantly via $\mathrm{H}$-bonding. ${ }^{9}$ However, systems where benzimidazole units are employed as H-bond donors are comparatively less common and mostly interact with anions via the deprotonation mechanism. ${ }^{6}$ Caussey and Allen reported that benzimidazole diamides interact with anions through $\mathrm{H}$-bonding, and benzimidazole tautomerism affects the composition of the H-bonding array provided to the anion. ${ }^{10}$ Furthermore, Gale et al., reported that benzimidazole appended ureas bind anions through $\mathrm{H}$-bonding, and the tautomeric H-bonding structures of the anion complexes depend on the $\mathrm{H}$ bonding domain of the anions. ${ }^{11}$ These observations clearly reflect that the mode of interaction of pyrrole and benzimidazole units with anions basically depends on the basicity of the anion and the nature of the organic scaffold where it is incorporated.

Herein, we report new pyrrole-benzimidazole (PYBI) conjugates where the pyrrole unit is directly linked to the $\mathrm{C} 2$ position of the benzimidazole ring via its $\alpha$ carbon, along with their detailed anion binding behaviour (Figure 1). These new motifs have two preorganized heterocyclic N-H donor sites and represent larger, more extended and flexible binding domain for anions (owing to proton transfer between benzimidazole Nitrogens). Further, we wish to explore the relative binding affinity of the two N-H donor units, along with the role of their acidity in anion selectivity. To increase the acidity difference between the two NH units and to obtain bet- ter colorimetric response for the recognition event, nitro group is incorporated at the benzimidazole periphery. It is assumed that insertion of nitro group will lead to facile anion induced charge transfer from the binding domain to the nitro group and yield a sharp color change. ${ }^{12}$ In addition to the basic conjugates, we have proposed two different sets of dimers (bis-PYBI) containing two PYBI units, where both the units are bridged via two different spacer motifs - first, an electronically non-coupled $s p^{3}$ carbon (analogous to dipyrromethanes) and second, they are coupled by a fluorescent quinoxaline moiety (analogous to quinoxaline bipyrrole). These dimeric motifs are expected to display cooperative binding effect towards anionic guests owing to varied interaction between the two PYBI units. This can be envisaged in view of their difference in electronic communication and spatial disposition, which may be further aided by proton shuttling ability of the two constituent benzimidazoles.

\section{Experimental}

\subsection{Materials and Methods}

4-nitro-o-phenylenediamine and tetrabutylammonium salts of anions employed for the study were purchased from Sigma Aldrich and were used as received. Pyrrole, $o$ phenylenediamine, phosphorous oxychloride, oxalyl chloride and nitrobenzene were purchased from Sisco Research Laboratories, India. Pyrrole, phosphorous oxychloride and solvents used in the synthesis were dried and distilled prior to use. Spectroscopic grade DMSO (Merck, India) was used for recording all spectrophotometric data. Melting points were determined with $\mathrm{MR}-\mathrm{Vis}^{+}$visual melting point range apparatus from LABINDIA Instruments Pvt. Ltd. IR spectra were recorded on a FT-IR spectrometer (JASCO FTIR model 5300 or NICOLET 5700). NMR spectra were obtained on Bruker $400 \mathrm{MHz}$ FT-NMR spectrometer operating at ambient temperature. TMS was used as internal standard for ${ }^{1} \mathrm{H}$ NMR spectra. LCMS spectra were recorded using Shimadzu- 
LCMS-2010 mass spectrometer. Elemental analyses were obtained using Thermo Finnigan Flash EA 1112 analyzer. UV-Vis spectra were recorded on a Perkin Elmer Lambda 35 UV-Vis spectrophotometer. Fluorescence spectra were recorded using Horiba Zobin Yovan Fluoromax-4 instrument.

\section{Results and Discussion}

\subsection{Synthesis and characterization}

Pyrrole-benzimidazole (PYBI) conjugates were conveniently synthesized by condensation of 1,2-phenylenediamine or $m$-nitro-1,2-phenylenediamine with the corresponding pyrrole carboxaldehyde derivative in nitrobenzene solvent at $120^{\circ} \mathrm{C}$ (see Supplementary Information). ${ }^{13}$ All compounds were characterized by standard spectroscopic techniques including ${ }^{1} \mathrm{H},{ }^{13} \mathrm{C}$ NMR spectroscopy, mass and elemental analysis (in SI). ${ }^{1} \mathrm{H}$ NMR spectra recorded in DMSO- $d_{6}$ at $298 \mathrm{~K}$ show two NH signals above $12 \mathrm{ppm}$ while pyrrole $\alpha$ - and $\beta$-Hs resonate around 6 and $7 \mathrm{ppm}$, respectively, for all the compounds (see Supplementary Information: Figures S1, S3, S5, S7 and S9). In the case of $\mathbf{2 b}$, benzimidazole $\mathrm{NH}$ signal splits into a doublet, which may be attributed to the $\mathrm{NH}$ tautomerism of benzimidazole moiety that becomes slower in presence of the nitro group. On the other hand, proton shuttling between the two benzimidazole nitrogens is probably too fast in the case of $\mathbf{1 a}, \mathbf{b}$ and 2a to be detected in the NMR time scale; therefore, it appears as a broad signal (see SI, Figures S1, S3 and S5). The absorption and emission spectra of compounds are shown in Figure 2 (Table 1). UV-Vis spectrum of compound 1a in DMSO revealed two absorption maxima at 312 and $327 \mathrm{~nm}$ (not much resolved). In addition, it shows fluorescence with emission maxima at 336 and $349 \mathrm{~nm}$. On the other hand, insertion of nitro derivative (i.e., 1b) results in well-resolved absorption bands with maxima at 299 and $387 \mathrm{~nm}$ indicating charge transfer nature of the transition. However, this molecule did not display any detectable fluorescence owing to the intramolecular photoinduced electron transfer (PET) from the excited fluorophore to the electron withdrawing nitro group (donor-excited PET; d-PET). ${ }^{14}$ Absorption spectrum of quinoxaline-bridged dimeric conjugate 3 , in DMSO, exhibits two absorption bands with maxima at 318 and $402 \mathrm{~nm}$ and it shows a relatively large red shifted emission at $560 \mathrm{~nm}$. This indicates facile conjugation between the two PYBI conjugates via quinoxaline moiety both in the ground and the excited state.
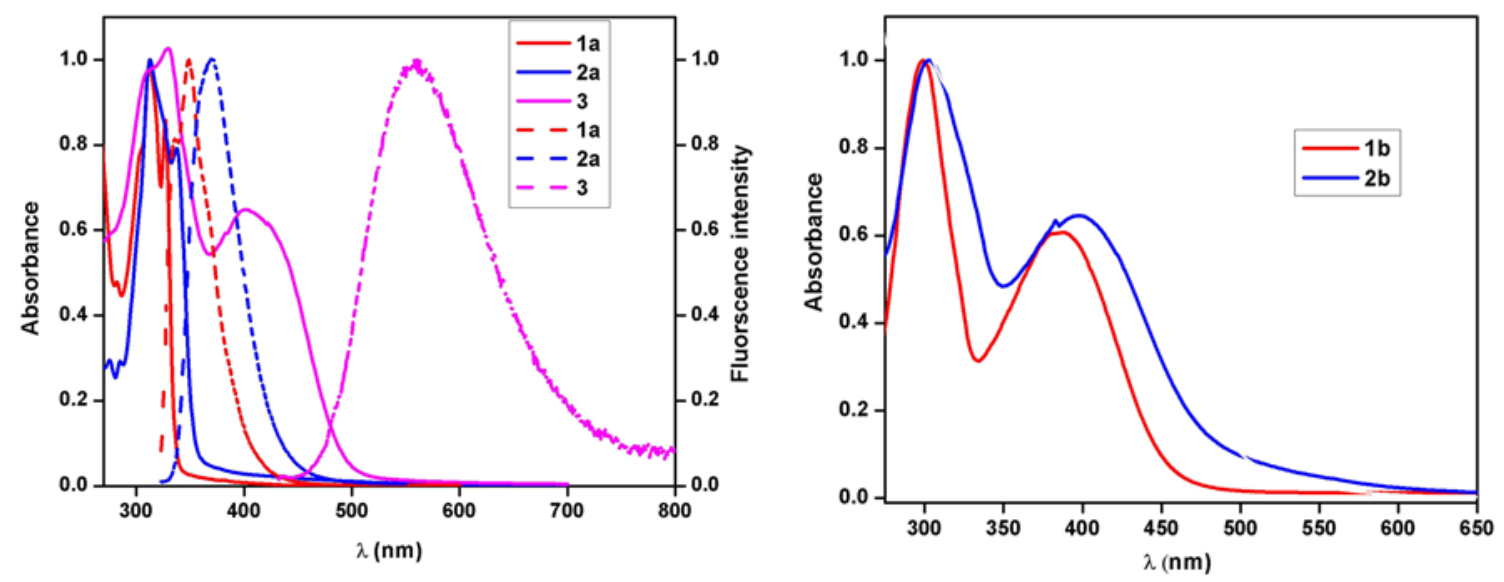

Figure 2. Normalized absorption (solid curves) and emission (dashed curves) spectra of the receptors in DMSO.

Table 1. Absorption and emission maxima along with log $\left(\varepsilon / \mathrm{M}^{-1} \mathrm{~cm}^{-1}\right)$ and Stoke's shift values for PYBI conjugates $\mathbf{1 - 3}$ in DMSO at $25^{\circ} \mathrm{C}$.

\begin{tabular}{lllll}
\hline Receptors & $\begin{array}{l}\text { Absorption in } \\
\text { DMSO } \lambda_{\max } \\
(\mathrm{nm})\end{array}$ & $\begin{array}{l}\log \\
\left(\varepsilon / \mathrm{M}^{-1} \mathrm{~cm}^{-1}\right)\end{array}$ & $\begin{array}{l}\text { Emission in } \\
\text { DMSO } \lambda_{\max } \\
(\mathrm{nm})\end{array}$ & $\begin{array}{l}\text { Stoke's } \\
\text { Shift }(\mathrm{nm})\end{array}$ \\
\hline $\mathbf{1 a}$ & 312,327 & $4.56,4.49$ & 337,349 & 10 \\
$\mathbf{1 b}$ & 299,387 & $4.35,4.13$ & - & - \\
$\mathbf{2 a}$ & 313,338 & $4.68,4.58$ & 361 (broad) & 23 \\
$\mathbf{2 b}$ & 303,398 & $4.55,4.36$ & - & - \\
$\mathbf{3}$ & 318,404 & $4.49,4.27$ & 563 & 159 \\
\hline
\end{tabular}




\subsection{Anion binding study}

3.2a Absorption and Emission Spectroscopy: Initial anion binding studies of the receptors were carried out at $298 \mathrm{~K}$, in DMSO, using UV-Vis spectroscopic titration method. The studies were done with $20 \mu \mathrm{M}$ solution of the receptors. Titrations were performed by adding known quantities of concentrated solution of the anions to the receptor solution. The anion solutions used in the titrations contained the receptor at the same concentration as the receptor solutions so as to nullify the dilution effect. The absorption data were fitted in the BenesiHildebrand plot of Connor equation (eq. 1) and from the ratio of the slope and intercept, binding constant $\mathrm{K} a$ was evaluated. ${ }^{15}$

$$
\frac{1}{\left[A-A_{0}\right]}=\frac{1}{S_{t} K_{a} b \Delta \varepsilon[L]}+\frac{1}{S_{t} b \Delta \varepsilon}
$$

Here, $A^{\circ}, A$ : Measured absorbance of the substrate in absence and in presence of anion respectively; $S_{t}$ : Total receptor concentration $(\mathrm{M}) ;[L]:$ Anion concentration (M); $K_{a}$ : Binding constant; $\Delta \varepsilon$ : Difference in molar absorptivity of the free receptor solution and the receptor-anion solution, and $b$ : Path length.

Anion screening experiment of 1a showed an appreciable change in the absorption spectrum for fluoride ion only, among the tested anions. Addition of TBAF resulted in $\sim 9 \mathrm{~nm}$ red shift of the two absorption bands (Figure 3). In order to evaluate the affinity of fluoride ion towards 1a, systematic spectrophotometric titration was carried out in DMSO with varying concentration of fluoride ion. During initial part of the titration (010 mole equiv.) a decrease in intensity of the band at $327 \mathrm{~nm}$ was observed. However, on further increase in $\mathrm{F}^{-}$concentration ( $>10$ mole equiv.), a new band appeared at $336 \mathrm{~nm}$ with concomitant decrease in the

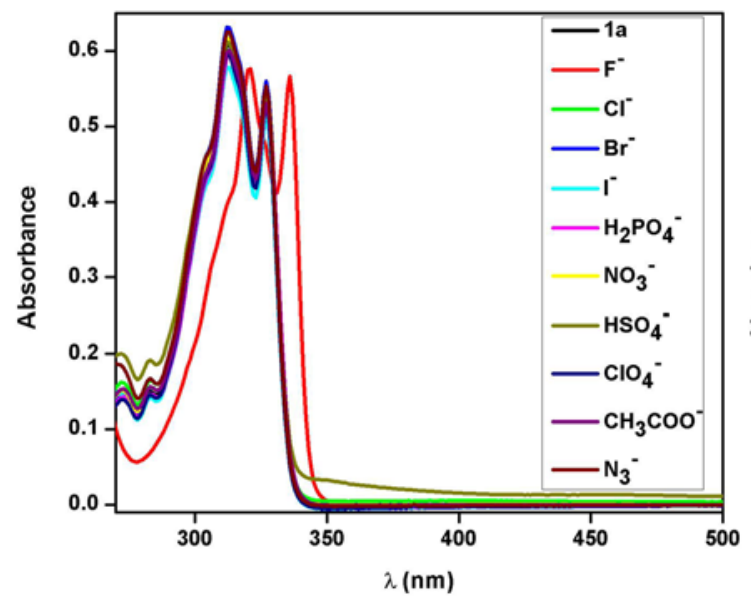

absorbance of the peak at $327 \mathrm{~nm}$. These observations suggested the possible involvement of two equilibrium process during the titration with varying concentration of fluoride. It is envisaged that initially for lower effective $\left[\mathrm{F}^{-}\right], \mathrm{H}$-bonding interaction $\left(\mathrm{N}-\mathrm{H} . . . \mathrm{F}^{-}\right)$could be attributed for the initial set of spectral changes. Further increase in $\left[\mathrm{F}^{-}\right]$might trigger the deprotonation of benzimidazole moiety. Comparatively higher acidity of the benzimidazole $\mathrm{N}-\mathrm{H}$ and the high thermodynamic stability of the $\mathrm{HF}_{2}^{-}$ion have favoured the deprotonation process. Deprotonation increases the electron density in $1 \mathbf{a}$ and consequently reduces the strength of the $\mathrm{H}$ bonding interaction of the pyrrolic $\mathrm{N}-\mathrm{H}$ with the fluoride ion. ${ }^{16}$

Anion screening experiment of receptor $\mathbf{1 b}$ displayed significant changes in UV-Vis spectrum, upon addition of $\mathrm{F}^{-}, \mathrm{CH}_{3} \mathrm{COO}^{-}$and $\mathrm{H}_{2} \mathrm{PO}_{4}^{-}$ions, and consequently colour of the solution changed from very light yellow to dark yellow with varying intensities (Figure 4). UV-Vis spectral titration revealed that with gradual addition of fluoride and acetate ions, the intensities of absorption bands at 299 and $387 \mathrm{~nm}$ decreased, while concomitantly, two new peaks appeared at 305 and $439 \mathrm{~nm}$ (Figure 5). The titrations revealed two clear isosbestic points at 324 and $404 \mathrm{~nm}$. Whereas, dihydrogenphosphate ion displayed relatively moderate response with slight change in the peak maxima (at 304 and $431 \mathrm{~nm}$ ). The interaction of $\mathbf{1 b}$ with anions resulted in increase in the electron density at the PYBI moiety and, as a consequence, facile charge transfer towards the acceptor $-\mathrm{NO}_{2}$ moiety stabilizes the excited state and hence causes a bathochromic shift in the absorption maxima, resulting in the change in color. ${ }^{12}$ This clearly reflects that nitro substitution at the benzimidazole periphery led to the colorimetric change upon addition of anions, however,

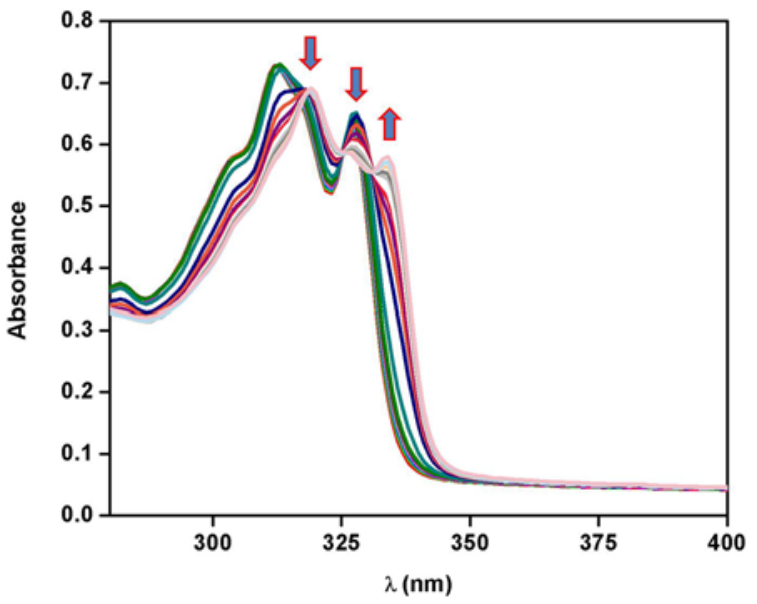

Figure 3. Left: UV-Vis spectra of $1 \mathbf{a}(20 \mu \mathrm{M})$ in DMSO in the absence and presence of different anions; right: UV-Vis spectra of $1 \mathbf{a}(20 \mu \mathrm{M})$ upon gradual addition of TBAF (0 to $15 \mathrm{mM})$. 

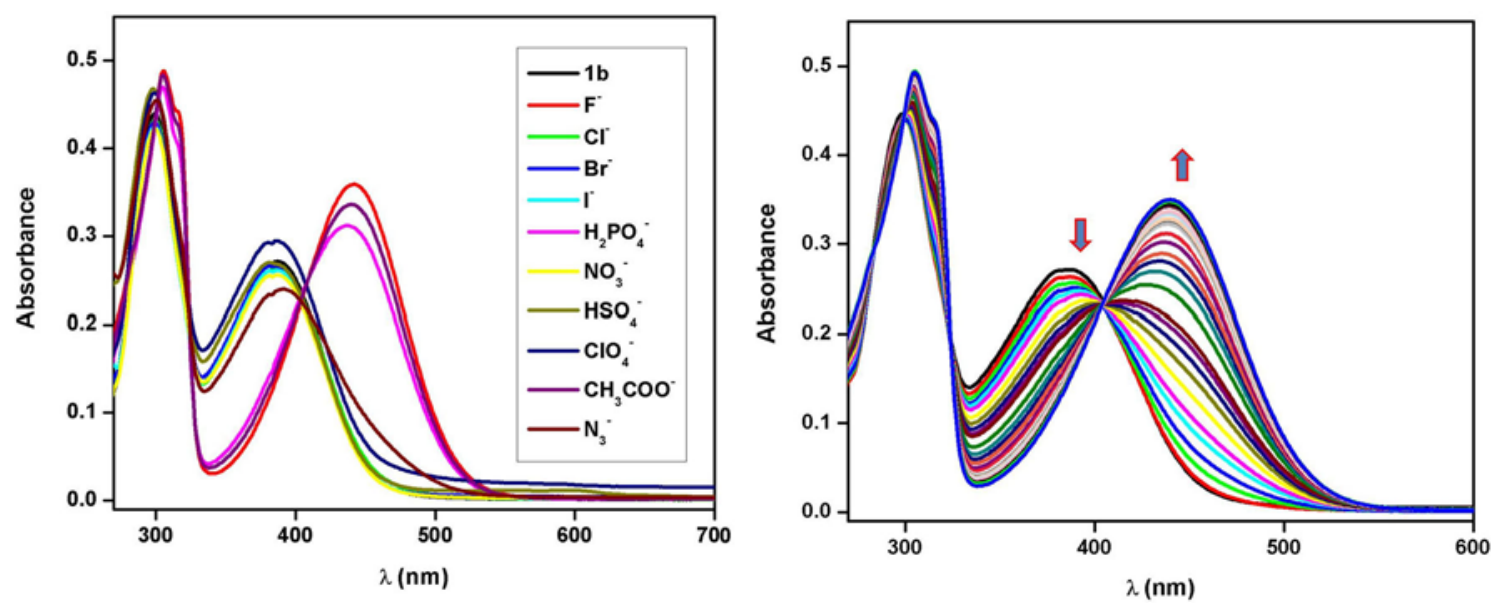

Figure 4. Left: UV-Vis spectra of $\mathbf{1 b}(20 \mu \mathrm{M})$ in DMSO in absence and presence of different anions; right: UV-Vis spectra of $\mathbf{1 b}(20 \mu \mathrm{M})$ in DMSO upon gradual addition of TBAF (0 to $0.35 \mathrm{mM})$.
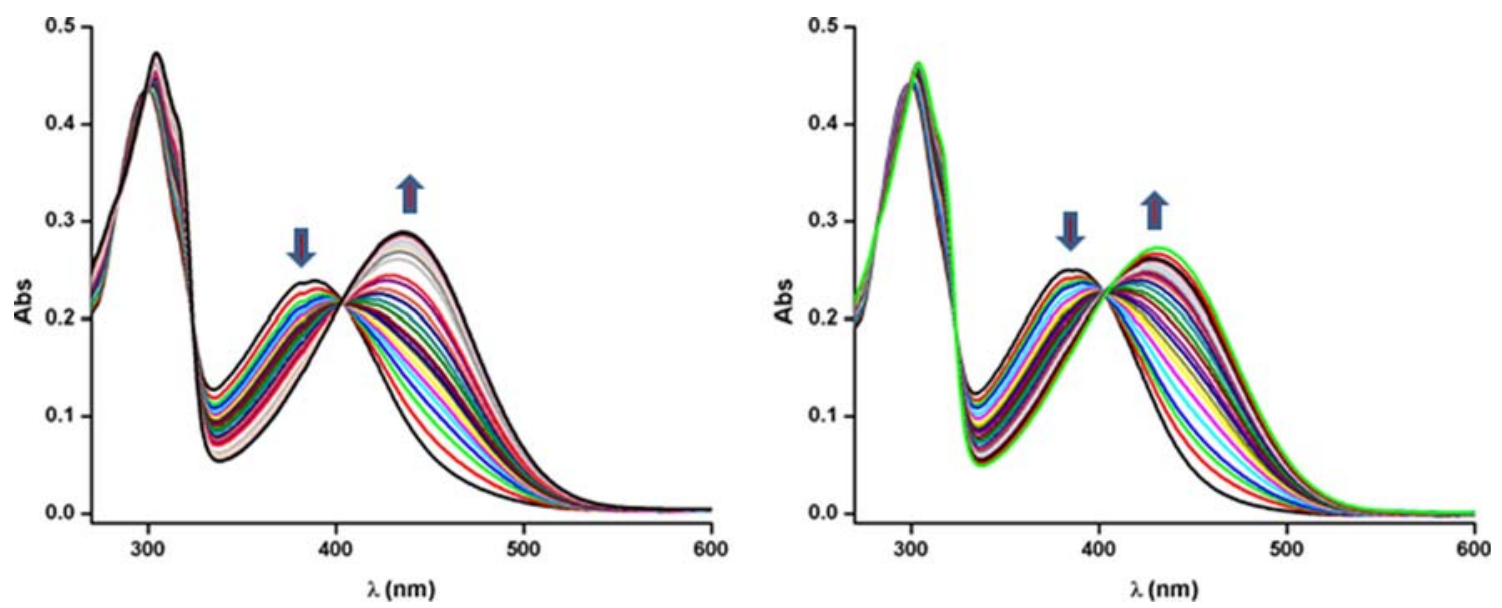

Figure 5. Left: Evolution of UV-Vis spectra of $\mathbf{1 b}(20 \mu \mathrm{M})$ in DMSO upon gradual addition of TBA $\left(\mathrm{CH}_{3} \mathrm{COO}\right)\left(4.3 \times 10^{-4} \mathrm{M}\right)$; right: UV-Vis spectra of $\mathbf{1 b}(20 \mu \mathrm{M})$ in DMSO upon gradual addition of $\mathrm{TBAH}_{2} \mathrm{PO}_{4}$ (0 to $\left.1.3 \mathrm{mM}\right)$.

at the expense of reduced selectivity towards anions. Job's plot analysis indicated the formation of 1:1 stoichiometric interaction, in the case of all the three anions.

Anion binding study of the bis-PYBI receptors shows very interesting host-guest chemistry. For example, depending upon the basicity and coordination ability of the anions, either positive or negative cooperative effect between the two constituent PYBIs could be clearly noticed. Calculated equilibrium constants $\left(\mathrm{K}_{a}\right)$ value from the UV-Vis data are given in Table 2. For calculation of equilibrium constant, the reaction between $1 \mathbf{a}$. $\mathrm{X}^{-}$and $\mathrm{X}^{-}$(where $\mathrm{X}^{-}$is anion) is considered. Although the values do not show any generalized trend w.r.t. basicity of the anions and the number of H-bond donor sites, a closer inspection reflects a few notable trends. First, the presence of two PIBYs, while it marginally enhances the binding affinity when bridged through insulating $s p^{3}$ carbon, it is enhanced by more than one order when bridged through conjugating quinoxaline moiety, upon complexation with fluoride ion. For example, compared to $1 \mathrm{a}, \mathrm{K}_{a}$ of fluoride complexation is increased by more than two fold in the case of $\mathbf{2 a}$; on the other hand, in the case of $\mathbf{3}, \mathrm{K}_{a}$ is increased by more than twelve fold. Similar trend was also noticed between $\mathbf{1 b}$ and $\mathbf{2 b}$ (i.e., $\mathrm{K}_{a}$ increased by three fold). This can be attributed to lack of extended conjugation in the case of $\mathbf{2 a}$ and $\mathbf{2 b}$, which could not stabilize the deprotonated hosts much. On the other hand, the positive cooperative effect between the two PYBIs during fluoride complexation by 3 could be ascribed to its extended conjugation that effectively stabilizes the negative charge upon decomplexation. Second, incorporation of electron withdrawing nitro group in the benzimidazole periphery (2b) and increased conjugation between the two PYBIs (3) led to reduced anion selectivity with additional guest 
Table 2. Acid-base equilibrium constant, $\mathrm{Ka}\left(\mathrm{M}^{-1}\right)$ of the receptors towards the interacting anions as determined by UV-Vis spectroscopy in DMSO at $25^{\circ} \mathrm{C}$.

\begin{tabular}{lcll}
\hline Host & $\mathrm{F}^{-}$ & $\mathrm{CH}_{3} \mathrm{COO}^{-}$ & $\mathrm{H}_{2} \mathrm{PO}_{4}^{-}$ \\
\hline $\mathbf{1 a}$ & $8.45 \times 10^{2}$ & - & - \\
$\mathbf{1 b}$ & $1.20 \times 10^{4}$ & $6.03 \times 10^{4}$ & $6.30 \times 10^{3}$ \\
$\mathbf{2 a}$ & $1.90 \times 10^{3}$ & - & - \\
$\mathbf{2 b}$ & $3.62 \times 10^{4}$ & $1.24 \times 10^{4}$ & $7.84 \times 10^{3}$ \\
$\mathbf{3}$ & $2.01 \times 10^{4}$ & $8.72 \times 10^{4}$ & $9.4 \times 10^{3}$ \\
\hline
\end{tabular}

binding towards acetate and dihydrogen phosphate ions by these hosts (Figures S37 and S49 in Supplementary Information). Surprisingly, complexation of acetate ion with $\mathbf{2 b}$ resulted in reduced affinity compared to that of $\mathbf{1 b}$ by about five times, whereas dihydrogen phosphate ion complexation led to marginal increase in $\mathrm{K}_{a}$ (ratio of $\mathbf{2 b} / \mathbf{1 b} \sim 1.25$ ). This type of negative cooperative effect between the two PYBIs could be explained on the basis of competition between them to bind the bidentate acetate ion. Whereas, the relatively larger size and presence of additional binding sites in the case of $\mathrm{H}_{2} \mathrm{PO}_{4}^{-}$ion possibly reduced the negative cooperative effect.

Fluorescence spectroscopic titration studies were also performed in order to check the ability of these receptors to function as fluorometric anion sensors. Among the receptors synthesized, nitro analogues are non-fluorescent (fluorescence is below detection limit). Emission studies were carried out with $1 \mu \mathrm{M}$ solution of the remaining three receptors; i.e., 1a, $\mathbf{2 a}$ and $\mathbf{3}$. Like the UV-Vis spectroscopy observation, remarkable quench- ing of fluorescence of receptors 1a and 2a was observed upon addition of $\mathrm{F}^{-}$ion, whereas no significant change in the fluorescence intensity could be noticed in the case of other anions (see Supplementary Information). This observation further suggests interaction of receptors 1a and $\mathbf{2 a}$ with fluoride ion only. In the case of receptor $\mathbf{3}$, addition of $\mathrm{F}^{-}, \mathrm{CH}_{3} \mathrm{COO}^{-}$and $\mathrm{H}_{2} \mathrm{PO}_{4}^{-}$ion resulted in almost complete quenching of its fluorescence but with different affinity. This may be ascribed to intramolecular photoinduced electron transfer (PET) and anion complexation triggered the electron transfer from the benzimidazole moiety to the ground state of the quinoxaline moiety.

3.2b ${ }^{1}$ H NMR study: To obtain further insight regarding the nature of interaction involved in the complexation process, ${ }^{1} \mathrm{H}$ NMR titrations were carried out in DMSO- $d_{6}$, with fluoride and acetate ions. In this experiment, the change in the ${ }^{1} \mathrm{H}$ NMR signals upon gradual addition of the anionic analyte was monitored.

Addition of 0.17 equiv. of TBAF to 1a in DMSO revealed disappearance of both the $\mathrm{NH}$ signals and instead a new broad peak arises at $\sim 12.1 \mathrm{ppm}$, which undergoes further broadening leading to complete disappearance upon subsequent additions of TBAF (Figure 6). After addition of $\sim 1.2$ equiv. of fluoride ion, a new broad triplet starts appearing at $16 \mathrm{ppm}$, indicating the formation of $\mathrm{HF}_{2}^{-}$ion, which indicates deprotonation of benzimidazole $\mathrm{NH}$ at higher concentration of $\mathrm{F}^{-}$. Aromatic proton signals displayed upfield shift upon addition of fluoride ion, indicating an increase in the electron density on both the pyrrole and benzimidazole rings due to deprotonation. The strong electrostatic repulsion from $\mathbf{1 b}^{-}$may be preventing the $\mathrm{F}^{-}$ion to
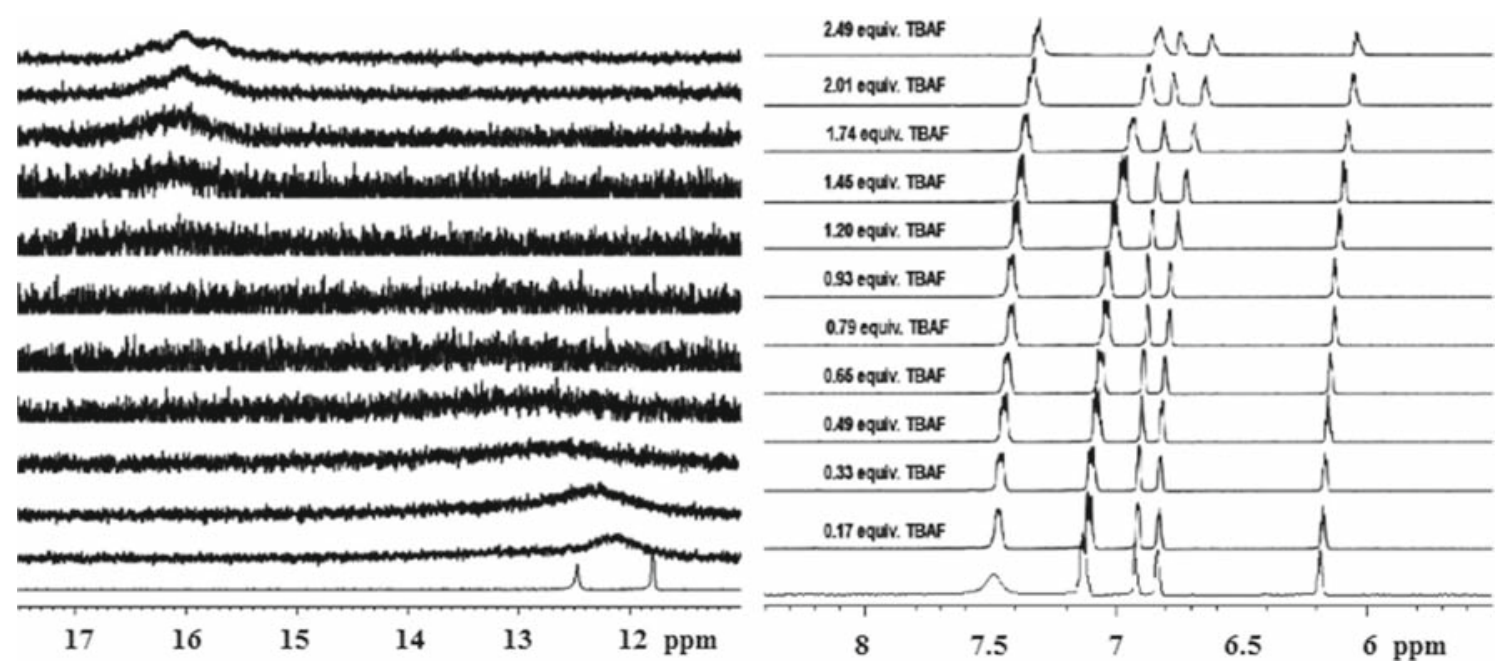

Figure 6. Changes in the ${ }^{1} \mathrm{H}$ NMR spectra of $\mathbf{1 a}(5 \mathrm{mM})$ in DMSO- $d_{6}$ upon gradual addition of TBAF $(0$ to $12 \mathrm{mM})$. 

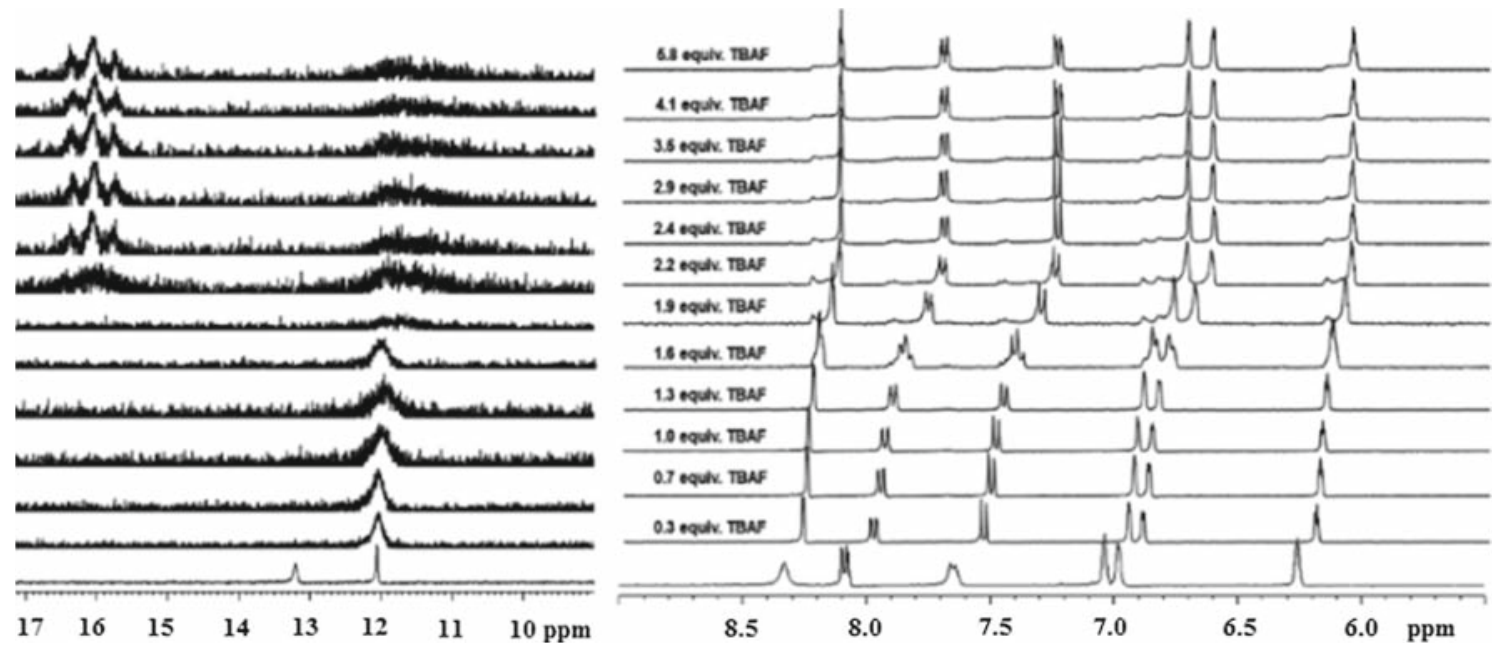

Figure 7. Changes in the ${ }^{1} \mathrm{H}$ NMR spectra of $\mathbf{1 b}(5 \mathrm{mM})$ in DMSO- $d_{6}$ upon gradual addition of TBAF $(0$ to $30 \mathrm{mM}$ ).
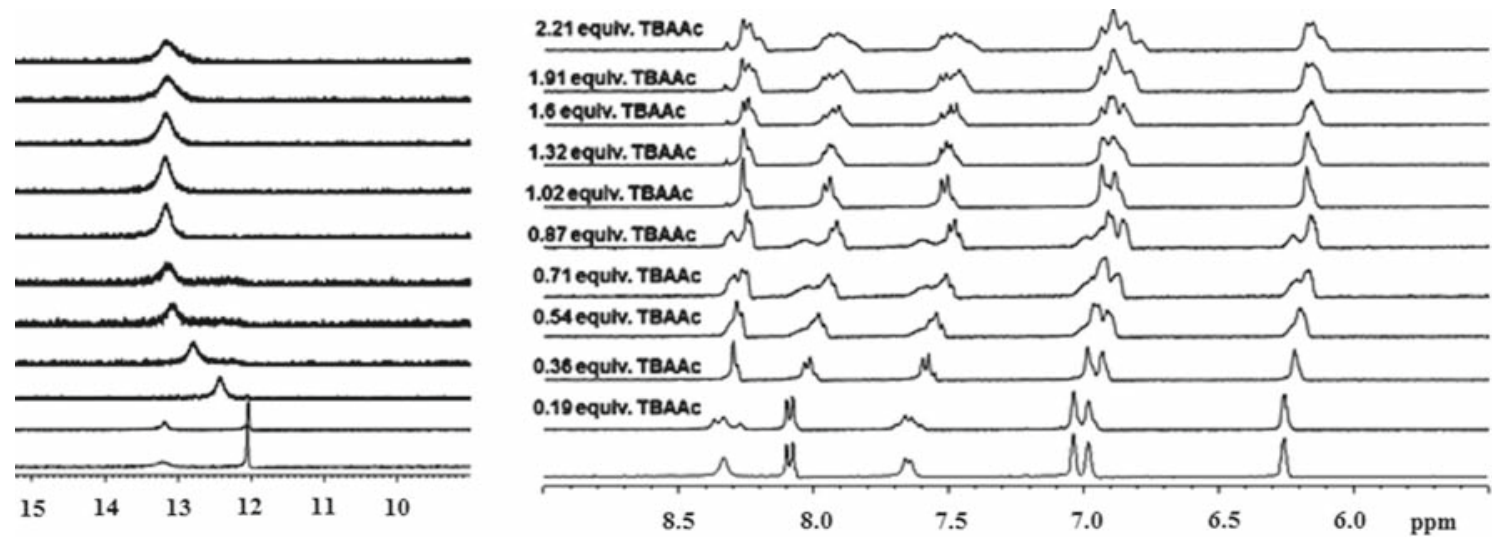

Figure 8. Changes in the ${ }^{1} \mathrm{H}$ NMR spectra of $\mathbf{1 b}(5 \mathrm{mM})$ in DMSO- $d_{6}$ upon gradual addition of TBAOAc (0 to $12 \mathrm{mM}$ ).

come closer to form H-bonding. The little downfield shift of the pyrrole $\mathrm{NH}$ proton indicates the involvement of pyrrole NH in weak H-bonding with the anion. However, broadening and subsequent disappearance of the signal upon increasing fluoride ion concentration might indicate the fast shuttling of the $\mathrm{NH}$ proton between the pyrrole and benzimidazole nitrogens, which is probably too fast to be detected in the NMR time scale (SI). On the other hand, titration of $\mathbf{1 b}$ with fluoride ion showed deprotonation of the benzimidazole $\mathrm{NH}$, while pyrrolic $\mathrm{NH}$ gradually broadens with slight upfield shift (Figure 7). The upfield shift of the pyrrolic NH is attributed to the increase in the electron density in the PYBI moiety, owing to the deprotonation of the benzimidazole $\mathrm{NH}$. This probably reduces the hydrogen bonding interaction between the pyrrole $\mathrm{NH}$ and fluoride ion. This observation confirmed that the selection of the $\mathrm{NH}$ unit for interaction by anion is driven by the acidity of the $\mathrm{NH}$. Titration of $\mathbf{1 b}$ with acetate ion revealed disappear- ance of the benzimidazole $\mathrm{NH}$ and downfield shift of the pyrrole NH with concomitant upfield shift of the aromatic protons (Figure 8). This observation indicates that more acidic benzimidazole $\mathrm{N}-\mathrm{H}$ proton gets deprotonated and pyrrole $\mathrm{N}-\mathrm{H}$ is involved in a relatively stronger $\mathrm{H}$-bonding (than with fluoride ion) with the protonated guest, possibly owing to its complementary bidentate coordination mode (Figure S29, in SI). Furthermore, titration of $\mathbf{2} \mathbf{b}$ with fluoride and acetate ions displayed similar binding patterns, as observed in the case of $\mathbf{1 b}$ (SI). ${ }^{1} \mathrm{H}$ NMR titration of receptor 3 with fluoride ion showed two new peaks at 20.5 and $16 \mathrm{ppm}$, along with a very broad peak between 12 and 16 ppm indicating the very slow kinetics of the binding and deprotonation equilibrium (Figure 9). Interestingly, gradual addition of TBAF up to $\sim 2$ equiv. resulted in sharpening of the peaks at 20.5 and $16 \mathrm{ppm}$ with concomitant loss of the the broad peak between 12 to $16 \mathrm{ppm}$. Further addition of TBAF resulted in upfield shift of the peak at $20.5 \mathrm{ppm}$ 

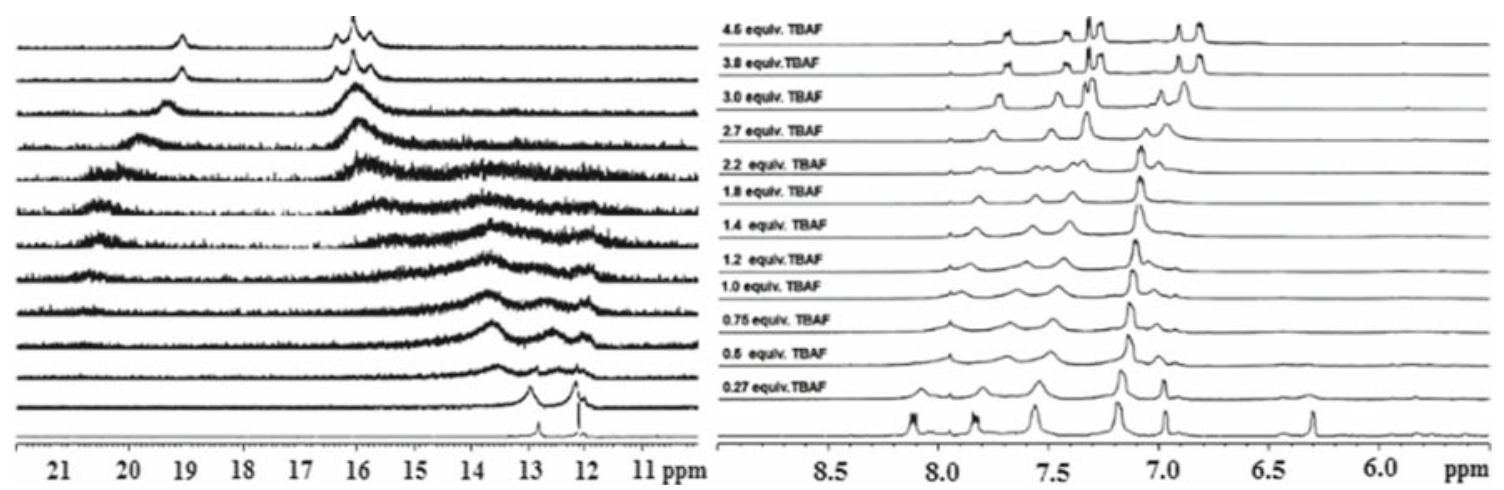

Figure 9. Changes in the ${ }^{1} \mathrm{H}$ NMR spectra of $3(5 \mathrm{mM})$ in DMSO- $d_{6}$ upon gradual addition of TBAF $(0$ to $25 \mathrm{mM}$ ).

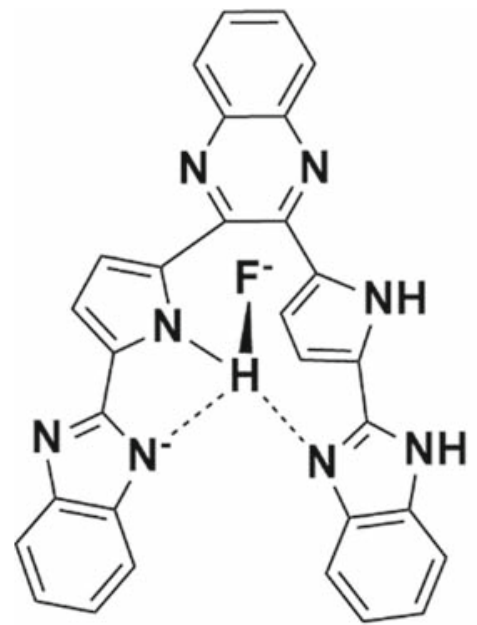

Complex A

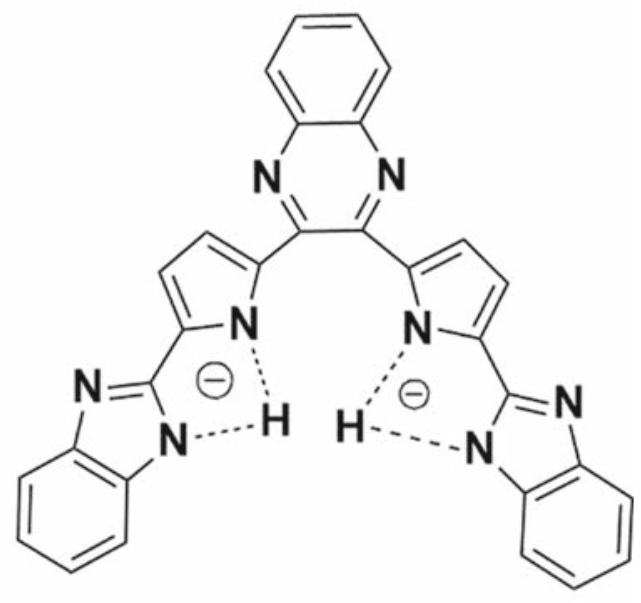

Complex B

Figure 10. Probable H-bonding structures of mono- and di-deprotonated forms of $\mathbf{3}$.

to $19 \mathrm{ppm}$, while the broad peak at $16 \mathrm{ppm}$ resolved into a triplet without undergoing shift. The peak at 20.5 ppm emerging after addition of 1 equiv. of fluoride ion (with slight upfield shift of both uncomplexed benzimidazole and pyrrole signals), may possibly be attributed to deprotonation of one of the benzimidazole moiety, followed by strong complexation of one of the pyrrolic $\mathrm{NH}$ with fluoride ion and benzimidazole Nitrogen (Figure 10, Complex A). On the other hand, evolution of the signal corresponding to $\mathrm{HF}_{2}^{-}$ion indicates the deprotonation of the benzimidazole protons, and the appearance of the broad peaks in between 12 and $16 \mathrm{ppm}$ signifies the intramolecular proton migration in the dianionic $3^{2-}$ species. Possibly, the pyrrolic NHs migrated towards the benzimidazole nitrogens and trapped inside the dianionic binding domain, by forming strong $\mathrm{N}-\mathrm{H}$... $\mathrm{N} \mathrm{H}$-bonding within the cavity resulting in the peak at $19 \mathrm{ppm}$ (Figure 10, Complex B). ${ }^{17}$ Further, titration of $\mathbf{3}$ with acetate ion showed similar type of changes in the $\beta$-CH pyrrolic region while no new signal was observed in the downfield region, as seen in the case of fluoride ion binding (see SI). Upon increasing the amount of acetate ion, pyrrole NH peaks get broadened without any noticeable shift. The results of ${ }^{1} \mathrm{H}$ NMR titration experiment corroborated the observations of the UV-Vis study, which suggested the presence of two equilibrium processes in the case of $\mathbf{1 a}$ and $\mathbf{2 a}$, namely, the $\mathrm{H}$-bonded adduct formation for relatively lower $\mathrm{F}^{-}$concentration, whereas at higher concentration, Bronsted acid-base equilibrium prevails. However, in the case of nitro derivatives ( $\mathbf{1 b}$ and $\mathbf{2 b}$ ), addition of fluoride ion leads to immediate deprotonation of the benzimidazole $\mathrm{NH}$ and subsequent charge transfer to the nitro group leading to color change. Incorporation of nitro group in the benzimidazole periphery drastically enhances the acidity of the benzimidazole NH compared to the pyrrole $\mathrm{NH}$, thereby increasing its deprotonation tendency. Receptor 3 also follows the deprotonation mechanism. 


\section{Conclusions}

A family of colorimetric chemosensors based on pyrrolebenzimidazole conjugates (PYBI) were synthesized and their anion recognition behaviour was investigated in detail. Receptor 1a and $\mathbf{2 a}$ act as colorimetric sensors for fluoride ion only. The ${ }^{1} \mathrm{H}$ NMR titration experiment revealed that the binding of the fluoride ion is through $\mathrm{N}-\mathrm{H}$. . . $\mathrm{F}^{-}$interaction. However, addition of more than one equivalent of anion eventually led to the deprotonation. Further, we have observed that incorporation of nitro group upon benzimidazole periphery induces the colorimetric response (in case of $\mathbf{1 b}$ and $\mathbf{2 b}$ ) but at the expense of selectivity by exhibiting tendency towards binding with acetate and dihydrogenphosphate ions. This observation reveals that increasing the acidity of the H-bonding proton without affecting the receptor geometry sometimes leads to a drastic change in anion selectivity. Addition of fluoride ion to $\mathbf{1 b}$ and 2b deprotonates benzimidazole $\mathrm{NH}$, while reducing $\mathrm{H}$ bonding interaction with the pyrrolic NH. Acetate ion deprotonates benzimidazole $\mathrm{NH}$ and the corresponding conjugate acid; i.e., acetic acid forms strong $\mathrm{H}$-bonding with the receptor via complementary bidentate coordination mode. Like $\mathbf{1 b}$ and $\mathbf{2} \mathbf{b}$, receptor $\mathbf{3}$ interacts with fluoride and acetate ions, and relatively weakly with dihydrogenphosphate ion. Interestingly, fluoride ions abstract, stepwise, both the benzimidazole NHs of receptor 3 in a unique way and as a consequence, possibly forcing delocalization of pyrrolic $\mathrm{NHs}$ in the binding domain, as indicated by the highly deshielded proton signal ( $\sim 19 \mathrm{ppm})$, as well as a stronger colorimetric and fluorometric response.

\section{Supplementary Information (SI)}

Synthetic procedures, ${ }^{1} \mathrm{H}$ and ${ }^{13} \mathrm{C}$ NMR spectra, absorption and emission spectra, anion binding data and computational data are available in Supplementary Information at www.ias. ac.in/chemsci.

\section{Acknowledgements}

This work is supported by Council of Scientific \& Industrial Research (CSIR), India project No. 01(2449)/10/EMR-II (P K P) and the Department of Science \& Technology (DST), Government of India project No. SB/FT/CS-090-2014 (S. P. M.).

\section{References}

1. (a) Sessler J L, Gale P A and Cho W S 2006 In Anion Receptor Chemistry (Royal Society of Chemistry: Cambridge, UK); (b) Beer P D and Gale P A 2001 Anion recognition and sensing: The state of the art and future perspectives Angew. Chem. Int. Ed. 40 486; (c) Gale P A and Dehaen W 2010 In Anion Recognition in Supramolecular Chemistry (Springer: Berlin); (d) Langton M J, Serpell C J and Beer P D 2016 Anion recognition in water: Recent advances from a supramolecular and macromolecular perspective Angew. Chem. Int. Ed. 55 1974; (e) Elmes R B P and Jolliffe K A 2015 Anion recognition by cyclic peptides Chem. Commun. 51 4951; (f) Ashton T D, Jolliffe K A and Pfeffer F M 2015 Luminescent probes for the bioimaging of small anionic species in vitro and in vivo Chem. Soc. Rev. 44 4547; (g) Gale P A, Busschaert N, Haynes C J E, Karagiannidis L E and Kirby I L 2014 Anion receptor chemistry: Highlights from 2011 and 2012 Chem. Soc. Rev. 43 205; (h) Ballester P 2010 Anion binding in covalent and selfassembled molecular capsules Chem. Soc. Rev. 39 3810; (i) Bregovic V, Basaric N and Mlinaric-Majerski K 2015 Anion binding with urea and thiourea derivatives Coord. Chem. Rev. 29580

2. Busschaert N, Caltagirone C and Rossom W V 2015 Applications of supramolecular anion recognition Chem. Rev. 1158038

3. (a) Pérez-Casas C and Yatsimirsky A K 2008 Detailing hydrogen bonding and deprotonation equilibria between anions and urea/thiourea derivatives $\mathrm{J}$. Org. Chem. $\mathbf{7 3}$ 2275; (b) Elmes R B P, Turner P and Jolliffe K A 2013 Colorimetric and luminescent sensors for chloride: Hydrogen bonding vs deprotonation Org. Lett. 15 5638; (c) Agarwalla H, Jana K, Maity A, Kesharwani M K, Ganguly B and Das A 2014 Hydrogen bonding interaction between active methylene hydrogen atoms and an anion as a binding motif for anion recognition: experimental studies and theoretical rationalization $J$. Phys. Chem. A 118 2656; (d) Borah S, Phukan B, Konwar G, Mahanta S P and Gogoi N 2015 Phenolic oxime based receptors for selective detection of fluoride RSC. Adv. 5 75187

4. (a) Amendola V, Bergamaschi G, Boiocchi M, Fabbrizzi L and Milani M 2010 The squaramide versus urea contest for anion recognition Chem. Eur. J. 16 4368; (b) Rostami A, Colin A, Li X Y, Chudzinski M G, Lough A J and Taylor M S 2010 N,N'-diarylsquaramides: general, highyielding synthesis and applications in colorimetric anion sensing J. Org. Chem. 753983

5. (a) Sessler J L, Camiolo S and Gale P A 2003 Pyrrolic and polypyrrolic anion binding agents Coord. Chem. Rev. 240 17; (b) Saha I, Lee J T and Lee C - H 2015 Recent Advancements in calix[4]pyrrole-based anion-receptor chemistry Eur. J. Org. Chem. 3859; (c) Ding Y, Zhu W -H and Xie Y 2017 Development of ion chemosensors based on porphyrin analogues Chem. Rev. 117 2203; (d) Chang K -C, Minami T, Koutnik P, Savechenkov P Y, Liu Y and Anzenbacher Jr. P 2014 Anion binding modes in meso-substituted hexapyrrolic calix [4]pyrrole isomers J. Am. Chem. Soc. 136 1520; (e) Haketa Y, Takasago R and Maeda H $2016 \beta$-electronic system through a single NH moiety Chem. Commun. 52 7364; (f) Ding Y, Tang Y, Zhu W and Xie Y 2015 Fluorescent and colorimetric ion probes based on conjugated oligopyrroles Chem. Soc. Rev. 44 1101; (g) Misra R, Anand V G, Rath H and Chandrashekar T K 2005 Core-modified 
octaphyrins: Syntheses and anion-binding properties $J$. Chem. Sci. 11799

6. (a) Singh N and Jang D O 2007 Benzimidazolebased tripodal receptor: Highly selective fluorescent chemosensor for iodide in aqueous solution Org. Lett. 9 1991; (b) Lee D Y, Singh N, Kim M J and Jang D O 2011 Chromogenic and fluorescent recognition of iodide with a benzimidazole-based tripodal receptor Org. Lett. 13 3024; (c)Gale P A, Hiscock J R, Lalaoui N, Light M E, Wells N J and Wenzel M 2012 Benzimidazole-based anion receptors: Tautomeric switching and selectivity Org. Biomol. Chem. 10 5909; (d) Moon K S, Singh N, Lee $\mathrm{G} \mathrm{W}$ and Jang D O 2007 Colorimetric anion chemosensor based on 2-aminobenzimidazole: Naked-eye detection of biologically important anions Tetrahedron 63 9106; (e) Borah N, Gogoi A and Das G 2016 Competitive anion binding aptitude of benzimidazole and amide functionality of a non-symmetrical receptor in solid state and solution phase Supramolecular Chem. 28 275; (f) Wei T -B, Li W -T, Li Q, Qu W -J, Li H, Yan G -T, Lin Q, Yao $\mathrm{H}$ and Zhang $\mathrm{Y}-\mathrm{M} 2016$ A dual-channel chemosensor could successively detect $\mathrm{CN}^{-}$based on benzimidazolenaphthalene conjugate: reversible and reusable study and design of logic gate function Dyes Pigm. 140 47; (1) Saikia E, Dutta P and Chetia B 2017 A novel benzimidazolyl-based receptor for the recognition of fluoride and cyanide anion J. Chem. Sci. 129 1; (m) Das P, Mahato P, Ghosh A, Mandal A K, Banerjee T, Saha $\mathrm{S}$ and Das A 2011 Urea/thiourea derivatives and Zn(II)DPA complex as receptors for anionic recognition: a brief account J. Chem. Sci. 123175

7. Bordwell F G 1988 Equilibrium acidities in dimethyl sulfoxide solution Acc. Chem. Res. 21456

8. Camiolo S, Gale P A, Hursthouse M B and Light M E 2003 Nitrophenyl derivatives of pyrrole 2, 5-diamides: Structural behaviour, anion binding and colour change signalled deprotonation Org. Biomol. Chem. 1741

9. (a) Black C B, Andrioletti B, Try A C, Ruiperez C and Sessler J L 1999 Dipyrrolylquinoxalines: Efficient sensors for fluoride anion in organic solution J. Am.Chem.
Soc. 121 10438; (b) Sessler J L, Maeda H, Mizuno T, Lynch V M and Furuta H 2002 Quinoxalineoligopyrroles: improved pyrrole-based anion receptors Chem. Commun. 862

10. Causey C P and Allen W E 2002 Anion binding by fluorescent biimidazole diamides J. Org. Chem. 675963

11. Gale P A, Hiscock J R, Lalaoui N, Light M E, Wells N J and Wenzel M 2012 Benzimidazole-based anion receptors: tautomeric switching and selectivity Org. Biomol. Chem. 105909

12. (a) Suksai C and Tuntulani T 2003 Chromogenic anion sensors Chem. Soc. Rev. 32 192; (b) Martínez-Mánèz R and Sanceńon F 2006 Chemodosimeters and 3D inorganic functionalised hosts for the fluoro-chromogenic sensing of anions Coord. Chem. Rev. 250 3081; (c) Martínez-Mánèz R and Sanceńon F 2003 Fluorogenic and chromogenic chemosensors and reagents for anions Chem. Rev. 1034419

13. Zapata F, Caballero A, Tárraga A and Molina P 2010 Ferrocene-substituted nitrogen-rich ring systems as multichannel molecular chemosensors for anions in aqueous environment J. Org. Chem. 75162

14. Ueno T, Urano Y, Kojima H and Nagano T 2006 Mechanism-based molecular design of highly selective fluorescence probes for nitrative stress J. Am. Chem. Soc. 12810640

15. (a) Connors K A 1987 In Binding Constant Determination (New York: Wiley); (b) Schalley C and Hirose K 2007 In Analytical Methods in Supramolecular Chemistry (Germany: Wiley-VCH); (c) Benesi H A and Hildebrand J H 1949 A Spectrophotometric investigation of the interaction of iodine with aromatic hydrocarbons J. Am. Chem. Soc. 712703

16. Gale P A, Sessler J L, Allen W E, Tvermoes N A and Lynch V 1997 Calix[4]pyrroles: crim substitution and tunability of anion binding strength Chem. Commun. 665

17. Pietrzak M, Try A C, Andrioletti B, Sessler J L, Anzenbacher Jr. P and Limbach H - H 2008 The largest $15 \mathrm{~N}-15 \mathrm{~N}$ coupling constant across an NHN hydrogen bond Angew. Chem. Int. Ed. 471123 